\title{
Waiting Periods versus Early Innervation: The Development of Axonal Connections in the Zebra Finch Song System
}

\author{
Richard Mooney and Mahendra Rao \\ Division of Biology, California Institute of Technology, Pasadena, California 91125
}

\begin{abstract}
This study examines the development of two neural pathways within the zebra finch forebrain that function respectively in the juvenile acquisition and the adult production of learned song. In the adult male zebra finch forebrain, the song nuclei L-MAN and HVc both innervate nucleus RA; L-MAN plays a crucial role in juvenile song acquisition but, unlike HVc and RA, is not essential for adult song production. Previous studies have shown that HVC axons arrive at the dorsal border of RA as early as posthatch day 15 (day 15), and only enter the male RA after days 25-30, but never enter the female RA. The present study examines the development of axonal projections from L-MAN to RA and finds that, in contrast to HVc axons, L-MAN terminals are present within the male and female RA by day 15 , and persist there throughout adult life. Unlike RA-projecting HVC neurons, HVC neurons projecting to area $X$ innervate this target by day 20 . Like L-MAN, area $X$ plays a transient role in song acquisition. These results suggest that in the zebra finch forebrain, neural pathways essential to juvenile song learning develop before those needed for adult song production.

[Key words: song control nuclei, robust nucleus of the archistriatum (RA), lateral portion of magnocellular nucleus of the anterior neostriatum (L-MAN), caudal nucleus of the ventral hyperstriatum (HVC), waiting compartment, zebra finch]
\end{abstract}

Zebra finches (Taeniopygia guttata), like other oscine songbirds, possess specialized brain nuclei that mediate the acquisition and production of learned song. These synaptically interconnected song nuclei, known as the song system, are unique to the songbird brain (Kroodsma and Konishi, 1991), and function only to produce learned songs, not other, unlearned vocalizations (Simpson and Vicario, 1990). The song system is divided into two functionally distinct circuits (see Fig. 1), the first of which links the forebrain and the vocal musculature, and consists of the nucleus interfacialis (nIf), the caudal nucleus of the ventral hyperstriatum $(\mathrm{HVc})$, the robust nucleus of the archistriatum (RA), and the hypoglossal motor neurons (nXIIts) that innervate the syringeal muscles used in singing. This circuit has a spe-

\footnotetext{
Received Dec. 28, 1993; revised Apr. 15, 1994; accepted Apr. 27, 1994.

We thank Dr. Mark Konishi, in whose lab this work was performed, Gene Akutagawa for training and technical assistance, Drs. Scott Fraser and Nancy O'Rourke for assistance with confocal microscopy, and Drs. Carla Shatz and

Allison Doupe for comments and criticism with respect to the manuscript.

Correspondence should be addressed to Richard Mooney, Department of Neurobiology, Box 3209, Duke University Medical Center, Durham, NC 27710.

Copyright $\odot 1994$ Society for Neuroscience $0270-6474 / 94 / 146532-12 \$ 05.00 / 0$
}

cialized vocal motor role, since it displays increased neuronal activity before and during singing (McCasland, 1987), and because bilateral lesions of HVc or RA selectively block song (Nottebohm et al., 1976), even though other, unlearned vocalizations remain unaffected (Simpson and Vicario, 1990). The second circuit, which connects HVc to RA indirectly, extends from $\mathrm{HVc}$ through area $\mathrm{X}$, to the medial nucleus of the dorsolateral thalamus (DLM), back to the magnocellular nucleus of the anterior neostriatum (MAN), the lateral portion (L-MAN) of which projects to RA (Nottebohm et al., 1982; Okuhata and Saito, 1987; Bottjer et al., 1989). This "recursive" loop lacks any obvious role in adult song production, since area $\mathrm{X}$ or L-MAN lesions made in the adult do not affect song quality (Bottjer et al., 1984; Sohrabji et al., 1990). In contrast, lesions made in either area $\mathrm{X}$ or L-MAN of juvenile birds severely disrupt normal song development (Bottjer et al., 1984; Sohrabji et al., 1990; Scharff and Nottebohm, 1991). Therefore, the recursive pathway plays a developmentally restricted role, essential during song learning, but unimportant to adult song production. One goal of this study is to determine whether these two pathways form their connections at different stages of the bird's development, given that the earliest stages of song learning actually precede the onset of song production (Immelman, 1969; Bohner, 1990).

A related issue addressed by this study is the role that innervation plays in controlling the sexual differentiation of the song system. In the zebra finch, the adult female song nuclei are reduced in total volume, cell size, and number when compared to the male (Gurney, 1981; Bottjer et al., 1986; Konishi and Akutagawa, 1987), with the behavioral consequence that only males can produce song (Nottebohm and Arnold, 1976; Gurney, 1982). This sexual dimorphism is the result of a hormonally regulated developmental process: female zebra finch chicks implanted with estrogen before day 45 (all dates in this study refer to posthatch age) develop masculinized song systems, and can produce song in adulthood (Gurney and Konishi, 1980; Gurney, 1981; Konishi and Akutagawa, 1987). The mechanism by which estrogen acts is still unknown, but in RA, its major effect is to prevent cell death: although male and female zebra finches begin posthatch life with a similar complement of RA neurons (Konishi and Akutagawa, 1985; Konishi and Akutagawa, 1990), these neurons atrophy and die in the female, but survive and grow in the male (Konishi and Akutagawa, 1987).

One hypothesis is that estrogen prevents RA cell death through an innervation-dependent mechanism, since the HVc axons that innervate RA do so in a developmentally retarded and sexually dimorphic fashion (Konishi and Akutagawa, 1985). In the male, HVc terminals "wait" along RA's dorsal border until day 30 , then rapidly fill RA between days 30 and 40 , reminiscent of the 
waiting behavior exhibited by geniculocortical axons in the kitten (Rakic, 1977; Shatz and Luskin, 1986; Ghosh and Shatz, 1992). In contrast, the female's HVc axons remain outside RA during the period of cell death, and provide little or no synaptic input to RA even in adulthood (Konishi and Akutagawa, 1985). Furthermore, RA atrophies when the HVc axon tract to RA is cut in day 15 males (Konishi and Akutagawa, 1987), and when $\mathrm{HVc}$ is lesioned in day 20 estrogen-treated female zebra finches (Herrmann and Arnold, 1991a), indicating that the steroidal milieu alone cannot maintain RA neurons deprived of innervation from $H V$ c. In order to clarify the role that innervation plays in the sexual differentiation of RA, we sought to determine when L-MAN axons form connections with RA, and whether this pathway was also sexually dimorphic.

\section{Materials and Methods}

Fixed brain DiI. HVc and L-MAN axon terminals in or near RA were labeled with DiI (1,1'-dioctadecyl-3,3,3',3'-tetramethylindocarbocyanine perchlorate; Molecular Probes, Inc.; Godement et al., 1987) either in fixed whole brain or in fixed parasagittal brain slices. Birds were anesthetized with a lethal dose of Equithesin $(>0.06 \mathrm{ml}$; scc Doupe and Konishi, 1991), and then perfused transcardially with warmed $\left(40^{\circ} \mathrm{C}\right)$, heparinized saline for $5 \mathrm{~min}$, followed by fixative (4\% paraformaldehyde and $0.1 \%$ glutaraldehyde in $0.025 \mathrm{M}$ phosphate buffer) for another 30 min. To label HVc or L-MAN axons in the whole brain, the fixed head was placed in a stereotaxic apparatus and either small pressure injections (World Precision Instruments Pico Pump) of concentrated $(25 \%$, w/v) DiI in absolute ethanol or Dil crystals were placed in the nucleus. To label HVc axons in fixed brain slices, 500- $\mu$ m-thick parasagittal slices of fixed brain tissue containing HVc and RA were cut with a vibratome and small pressure injections of Dil were made into HVc after locating it under transillumination with the aid of a dissecting microscope. Tissue was then stored in $4 \%$ paraformaldehyde in $0.025 \mathrm{M}$ phosphate buffer at $37^{\circ} \mathrm{C}$, for $2-4$ weeks to label $\mathrm{HVc}$ terminals, $6-10$ weeks for L-MAN terminals.

In vivo DiI. Stereotactic injections of Dil were made in vivo into the L-MAN or HVc of birds anesthetized with Equithesin. One hundred nanoliters of a $1 \%(\mathrm{w} / \mathrm{v})$ solution of DiI in absolute ethanol were injected into the target area with a $1 \mu \mathrm{l}$ Hamilton syringe. Optimal anterograde labeling required a $96 \mathrm{hr}$ survival time, as opposed to $24-48 \mathrm{hr}$ for retrograde transport. Vibratome sections $50-200-\mu \mathrm{m}$-thick were prepared from tissue following fixation as outlined above.

DiI-mediated photoconversion of $D A B$. In certain cases, the fluorescence emitted by the DiI-labeled material was used to photooxidize diaminobenzidine (DAB; Sigma) to produce a permanent, light opaque stain. The protocol was similar to that outlined elsewhere (Sandell and Masland, 1988). After photoconversion was complete, sections were washed, mounted on slides, air dried, dehydrated in $100 \%$ ethanol, cleared in xylene, and coverslippcd with Permount.

WGA-HRP. Birds were anesthetized with $0.02-0.04 \mathrm{ml}$ of Equithesin injected intramuscularly and placed in a stereotaxic apparatus; the scalp was retracted and a small window was made in the skull overlying $\mathrm{HVc}$. A glass electrode (Haer $\Omega$-dot borosilicate capillary glass, $1.2 \mathrm{~mm}$ diameter, with fiber), with a tip diameter of $\sim 15 \mu \mathrm{m}$, was filled by capillarity with a $2 \%(\mathrm{w} / \mathrm{v})$ solution of WGA-HRP (Sigma) in $0.1 \mathrm{M}$ ' Iris hydrochloride. Relying on stereotactic coordinates, the electrode was positioned in HVc, and the WGA-HRP solution was iontophoresed from the pipette tip with positive current pulses $(\sim 4 \mu \mathrm{A}), 5 \mathrm{sec}$ in duration, every $10 \mathrm{sec}$. Total injection times varied from 2 to $6 \mathrm{~min}$ in length.

After a $24-36 \mathrm{hr}$ survival period, birds were perfused as above, except that the fixative was $2 \%$ paraformaldehyde and $2 \%$ glutaraldehyde in $0.05 \mathrm{M}$ sodium phosphate buffer $(\mathrm{PB})$, cooled to $4^{\circ} \mathrm{C}$, followed by cooled $\left(4^{\circ} \mathrm{C}\right) 10 \%$ sucrose in $0.05 \mathrm{M} P B$. The brain was removed and allowed to sink overnight in $30 \%$ sucrose in $0.05 \mathrm{M}$ PB. Sections $30-90 \mu \mathrm{m}$ thick were cut with a freezing microtome and collected in $0.05 \mathrm{M} \mathrm{PB}$ on ice, rinsed three times with distilled water, and then incubated for $30 \mathrm{~min}$ in a tetramethylbenzidine/sodium nitroferrocyanide mixture in acetate buffer (Mesulam, 1978). Hydrogen peroxide was added at a final concentration of $0.006 \%$, and the reaction closely monitored. The reaction ultimately was quenched in $0.01 \mathrm{~m}$ sodium acetate buffer chilled to $4^{\circ} \mathrm{C}$. In some cases, ammonium molybdate was used to stabilize the reaction

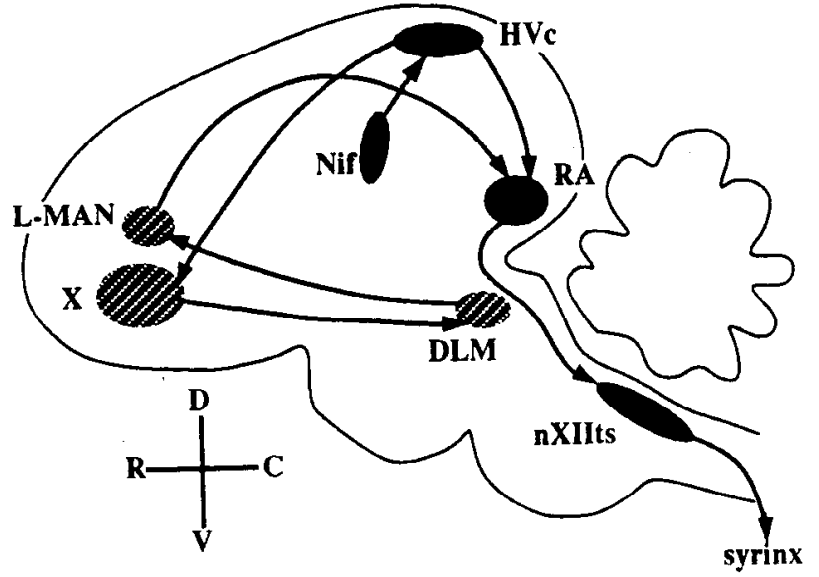

Figure 1. A simplified schematic of the adult male zebra finch song system, shown in parasagittal view. The direct vocal motor control pathway (solid black) includes the nucleus interfacialis ( Nif), the caudal nucleus of the ventral hyperstriatum $(H V C)$, the robust nucleus of the archistriatum $(R A)$, and the tracheosyringeal portion of the hypoglossal nucleus ( $n X I I t s$ ), which contains motor neurons that innervate the muscles of the syrinx, the avian song organ. The recursive pathway (crosshatched) also connects $\mathrm{HV}_{\mathrm{c}}$ to RA, via area $\mathrm{X}$, the dorsolateral nucleus of the medial thalamus $(D L M)$, and the lateral portion of the magnocellular nucleus of the anterior neostriatum $(L-M A N)$. Some nuclei have been omitted for clarity. $D$, dorsal; $V$, ventral; $R$, rostral; $C$, caudal.

product (Marfurt et al., 1988). Sections were mounted out of acetate buffer, air dried, cleared in xylene, and coverslipped with Permount. Alternate sections were stained with Neutral red to determine the location of the labeled material with respect to song nuclei.

Intracellular recordings in vitro. Complete details of the in vitro brain slice preparation have been described previously (Mooney and Konishi, 1991). Parasagittal slices ( $400 \mu \mathrm{m}$ thick) were equilibrated in an interface chamber (1-2 hr), and then transferred to a semisubmersion chamber warmed to $35^{\circ} \mathrm{C}$ and perfused with oxygenated artificial cerebrospinal fluid (ACSF) at a rate of 3 to $5 \mathrm{ml} / \mathrm{min}$. Bipolar tungsten electrodes were used to deliver brief $(100 \mu \mathrm{sec})$ extracellular electrical stimuli to fiber tracts within the slice preparation. Synaptic responses and action potentials were stored on a videocasette recorder (Sony SLO 1800) in pulse-code format (Neuro-Corder DR-484), and analyzed, both on and off line, with the aid of digital oscilloscope software written by Larry Proctor for a MASSCOMP Graphics workstation.

Intracellular staining techniques (biocytin). Intracellular staining with biocytin (Sigma) was achieved by impaling neurons with $80-150 \mathrm{M} \Omega$ electrodes filled with $2 \%$ biocytin in $2 \mathrm{M}$ potassium acetate (Horikawa and Armstrong, 1988). Biocytin was iontophoresed from the electrode with $0.6-1.5 \mathrm{nA}$ depolarizing current pulses, $1 \mathrm{sec}$ in duration, at a frequency of $0.5 \mathrm{~Hz}$. Optimal fills were obtained within $15-30 \mathrm{~min}$, and then the slices were placed in $4 \%$ paraformaldehyde in $0.025 \mathrm{M}$ phosphate buffer $\left(4^{\circ} \mathrm{C}\right)$ for at least $12 \mathrm{hr}$

Following fixation, slices were embedded in a gelatin-albumin mixture, and then vibratome sectioned to $100 \mu \mathrm{m}$ thickness. Sections were rinsed in $0.025 \mathrm{~m}$ phosphate-buffered saline (PBS), $\mathrm{pH} 7.40$, permeabilized $20-45 \mathrm{~min}$ in $0.25 \%$ Triton and $2 \%$ bovine serum albumin (BSA fraction V, Sigma) in PBS, rinsed in PBS, and then incubated for 6-12 $\mathrm{hr}$ in a solution of Avidin D HRP (Vector Labs, Inc.), diluted 1:100 in $2 \%$ BSA in PBS at $4^{\circ} \mathrm{C}$. After rinsing again with PBS, sections were incubated in a $0.05 \%$ DAB solution in PBS for $1 \mathrm{hr}$, and then hydrogen peroxide was added to the DAB solution at a final concentration of $0.02 \%$. Sections were monitored until a strong reaction product was visible, and then rinsed with PBS, mounted on slides, air dried, cleared with xylene, and coverslipped with Permount. Filled cells were reconstructed with the aid of a camera lucida and a $100 \times$ Zeiss oil immersion objective (1.3 NA).

Intracellular staining techniques (Lucifer yellow). A solution of 5-10\% Lucifer yellow CH (Aldrich) in 1.0-0.5 $\mathrm{M}$ lithium chloride was also used for intraneuronal staining (Stewart, 1978), occasionally adding formaldehyde at a final concentration of $3.7 \%$. Electrodes were identical to those employed with biocytin, except that the impedance was typically 100-200 M $\Omega$. Upon impalement, 1-2 nA hyperpolarizing current pulses 

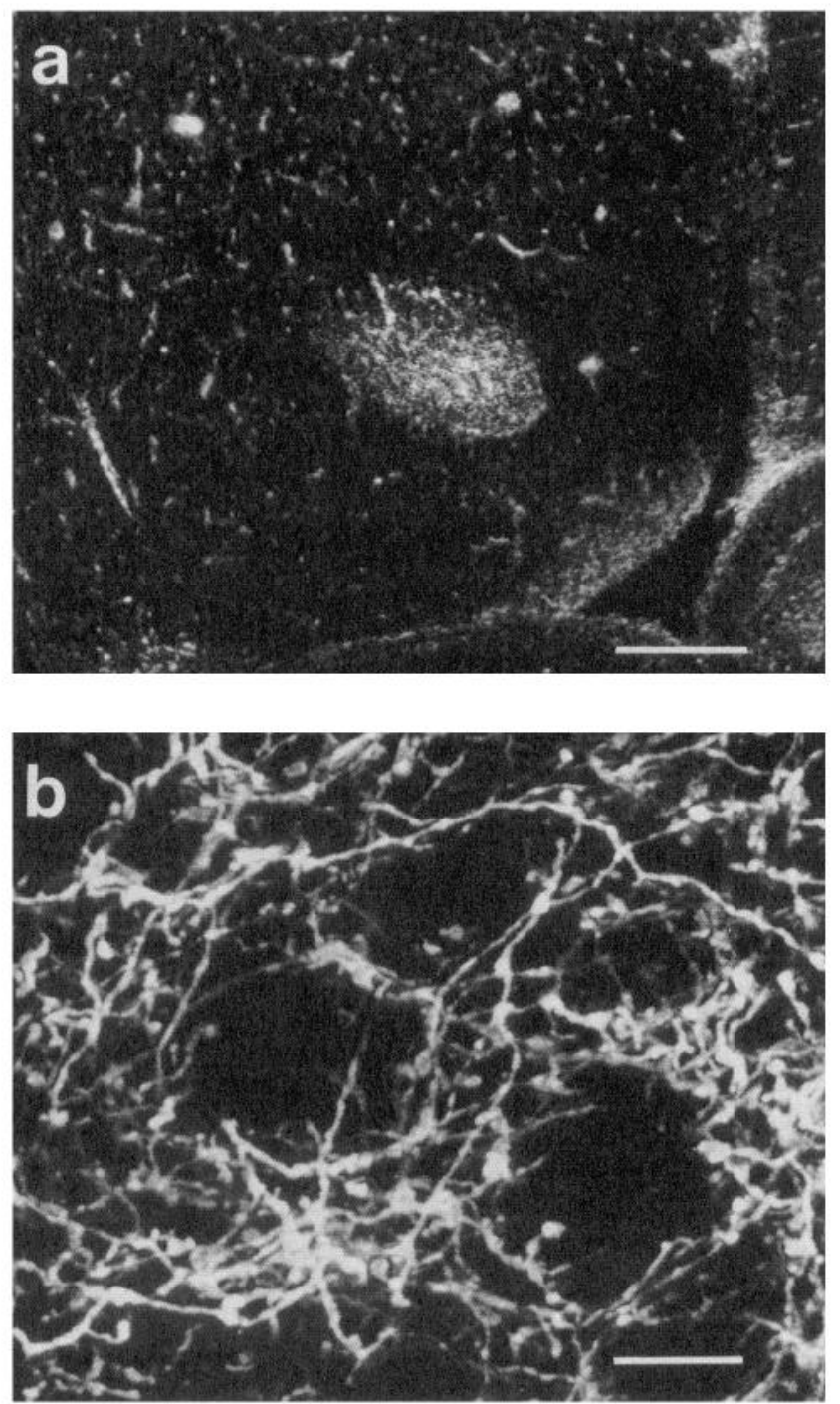

Figure 2. L-MAN terminals are present within RA before day 30. $a$, A combined bright-field and fluorescence confocal image of anterograde label within RA following an in vivo injection of DiI into the L-MAN of a day 15 male zebra finch (day 19 at time of perfusion). The white, oval structure in the center of the figure is the mass of L-MAN terminals filling RA. Section is in coronal orientation, with dorsal to the top and medial to the right; the cerebellum is visible to the right of the medial edge of the forebrain. $b$, A higher-magnification confocal image of DiIlabeled L-MAN axon terminals within RA from a day 30 male. Note the periodic swellings along the length of individual processes, which may be synaptic varicosities. Scale bars: $a, 400 \mu \mathrm{m} ; b, 10 \mu \mathrm{m}$.

( $2.5 \mathrm{~Hz}, 1: 1$ duty cycle) were passed through the electrode for 10-30 min. After filling several cells, slices were fixed in $4 \%$ paraformaldehyde in $0.025 \mathrm{M}$ PBS and stored at $4^{\circ} \mathrm{C}$. Slices were resectioned on a vibratome to a thickness of $200 \mu \mathrm{m}$, mounted on slides, and air dried.

Confocal microscopy. Confocal images were generated on a Bio-Rad 600 scanning laser confocal system mated to a Zeiss Axiovert microscope. A Kalman filter was used to enhance the signal to noise ratio of individual optical sections and, in some cases, edge-enhancement software was used to heighten contrast. Figures in which whole neurons are illustrated represent the two-dimensional projection of 5-20 separate optical sections, made in $0.25-2.5 \mu \mathrm{m}$ increments along the $\mathrm{z}$-axis. In some cases, separate confocal images made of the same area under bright-field and epifluorescence illumination were merged to form a single image showing both anatomical landmarks and fluorescently labeled structures.

\section{Results}

We examined the development of the L-MAN projection to RA from day 12 through adulthood in male and female zebra finches. We were especially interested in the period before day 30 because we wanted to know (1) what synaptic connections exist between song nuclei before HVc axons innervate RA, that is, during the earliest stages of song acquisition (Bohner, 1990); (2) whether the "waiting" behavior exhibited by HVc axons was unique to this projection, or reflected a general inability of RA neurons to support extrinsic input before the end of the fourth posthatch week; and (3) whether the L-MAN projection to RA was sexually dimorphic, like that between HVc and RA.

\section{$L-M A N$ axonal projections to $R A$ before day 30}

L-MAN terminals were present within both the male and female RA as early as day 15 . DiI was injected in vivo into the L-MAN of seven zebra finches younger than day 25 , including one day 12 , two day 15 , one day 17 , and one day 20 female, as well as two day 15 males. Regardless of the sex or age of the bird in which L-MAN was injected, fluorescently labeled terminals were present within RA 3-4 d following the injection (see Fig. 2a).

In order to obtain higher resolution images of these L-MAN terminals, confocal images were made of labeled terminals within RA, following DiI injection into the L-MAN in fixed brain tissue of a day 30 male. Single optical sections revealed a dense, fibrous meshwork, punctuated by characteristic "holes" of 10$20 \mu$ diameter, in which label was absent (see Fig. $2 b$ ). Nuclei and nucleoli were found in these "holes" when the same optical section was examined under phase contrast optics, suggesting that the holes were formed by RA cell bodies. Labeled fibers had occasional branches and small swellings along their length (see Fig. 2b).

\section{$L-M A N$ axonal projections to $R A$ after day 30}

L-MAN terminals were readily detected within both the male and female RA after day 30. The L-MAN in four birds (one male and three females), day 50 or older, was injected with DiI, either in fixed or living brain tissue. In all cases, L-MAN injections labeled terminals within RA. The three female birds were day 50, 70, and 90 at the time of the injection, the male was greater than day 90 . At these ages, RA is extremely sexually dimorphic, atrophied in the female, and hypertrophied in the male. In either sex, the labeled L-MAN terminals were confined within RA, and did not appear to extend beyond its borders (data not shown).

\section{Other areas labeled following $L-M A N$ injections}

Regardless of the bird's age or sex, injections of DiI in L-MAN also resulted in strong retrograde label within the thalamus. Retrogradely labeled cell bodies were confined to a dorsal and posterior part of the thalamus about $1-1.5 \mathrm{~mm}$ from the midline, thought to be DLM (see Fig. 1; data not shown).

\section{HVc axonal projections}

Previous studies have revealed that HVc axon terminals actually wait at the border dorsal to RA before entering the nucleus. Tritiated-proline injections made into the HVc of male zebra finches at different ages have shown that although HVc axons reach RA's dorsal border as early as day 15 , they do not enter the nucleus until 10-15 d later (Konishi and Akutagawa, 1985). Although proline is a sensitive anterograde tracer, it does not 
permit high-resolution imaging of the labeled axon terminals, nor does it label cells retrogradely. Therefore, other anterograde and retrograde tracers were used to provide more information about $\mathrm{HVc}$ axons during the waiting period.

In six zebra finches younger than day 25 (three males and three females), HVc was injected with either DiI or WGA-HRP. In all cases, regardless of sex, the bulk of the transported label was concentrated just outside RA, and especially along its dorsal edge. Figure $3 a$ typifies the labeling found outside RA, following injections of DiI into HVc. We will refer to this region abutting the dorsal border to RA as the "waiting compartment." Even when extremely small injections of DiI were made into $\mathrm{HVc}$ in fixed brain slices, labeled terminals were still confined to the waiting compartment. The pattern of HVc terminal distribution within the waiting compartment contrasts markedly with the HVc axonal projection to RA in the adult ( $>$ P90) male finch, in which HVc fibers run in highly fasciculated bundles to RA, then defasciculate and elaborate dense terminal fields in the nucleus (see Fig. 3b).

In direct contrast to the $\mathrm{HVc}$ axonal projection to the waiting compartment, HVc axons projecting to area $\mathrm{X}$ were already present within this target by day 20 . The pattern of anterograde label within area $\mathrm{X}$, resulting from WGA-HRP injections into $\mathrm{HVc}$, is shown in parasagittal view in sections 4-8 in Figure 4, and in a higher-power dark-field image in Figure $5 c$. Furthermore, injections into $\mathrm{HVc}$ at or before day 20 retrogradely labeled clusters of cells within both the forebrain and thalamus (see Fig. 4). The anatomical location of these clusters, as determined by counterstaining, was within the medial portion of MAN (see Fig. 4, sections 9 and 10; Fig. 5a), the nucleus interfacialis (nIf; Fig. 4, sections 4-8; Fig. $5 b$ ), and the thalamic nucleus Uva (Fig. 4, sections 7 and 8; Fig. 5d).

In order to rule out the possibility that developmental variation between individual animals might erroneously suggest that L-MAN and HVc terminals enter RA at different ages, the right L-MAN and the left HVc of a day 15 male finch were injected with DiI in order to visualize L-MAN and HVc fibers in the same animal. Although the RA on the side receiving the L-MAN injection was filled with fluorescently labeled terminals, the waiting compartment, but not RA, was fluorescently labeled on the side receiving the $\mathrm{HVc}$ injection (data not shown).

To clarify further the trajectory of the HVc and L-MAN fiber pathways in an adult male finch, DiI crystals were implanted in the left L-MAN and the right HVc of a previously fixed brain. After transport was complete, the brain was sectioned in the coronal plane, allowing the location of the two fiber pathways to be compared side by side (see Fig. 6). Labeled L-MAN axons ran caudally in the lamina hyperstriatica $(\mathrm{LH})$ toward $\mathrm{HVc}$, consisting of a broad band of fibers that swept laterally as they traveled caudally. L-MAN axons turned and cascaded in the ventral direction upon reaching a rostrocaudal point approximately even with, but slightly lateral to, HVc. After descending ventrally to a level approximately even with RA, L-MAN axons executed a sharp, right-angle turn in the medial direction, then entered RA along its lateral face. In contrast, HVc axons ran dorsoventrally in highly fasciculated bundles toward RA, and proceeded to enter RA along its dorsal edge. Most labeled HVc axons were situated medial to the L-MAN fiber pathway.

\section{Physiology of waiting compartment neurons}

One possibility is that HVc axon terminals, while situated along the dorsal border to RA between day 15 and 30 , actually form
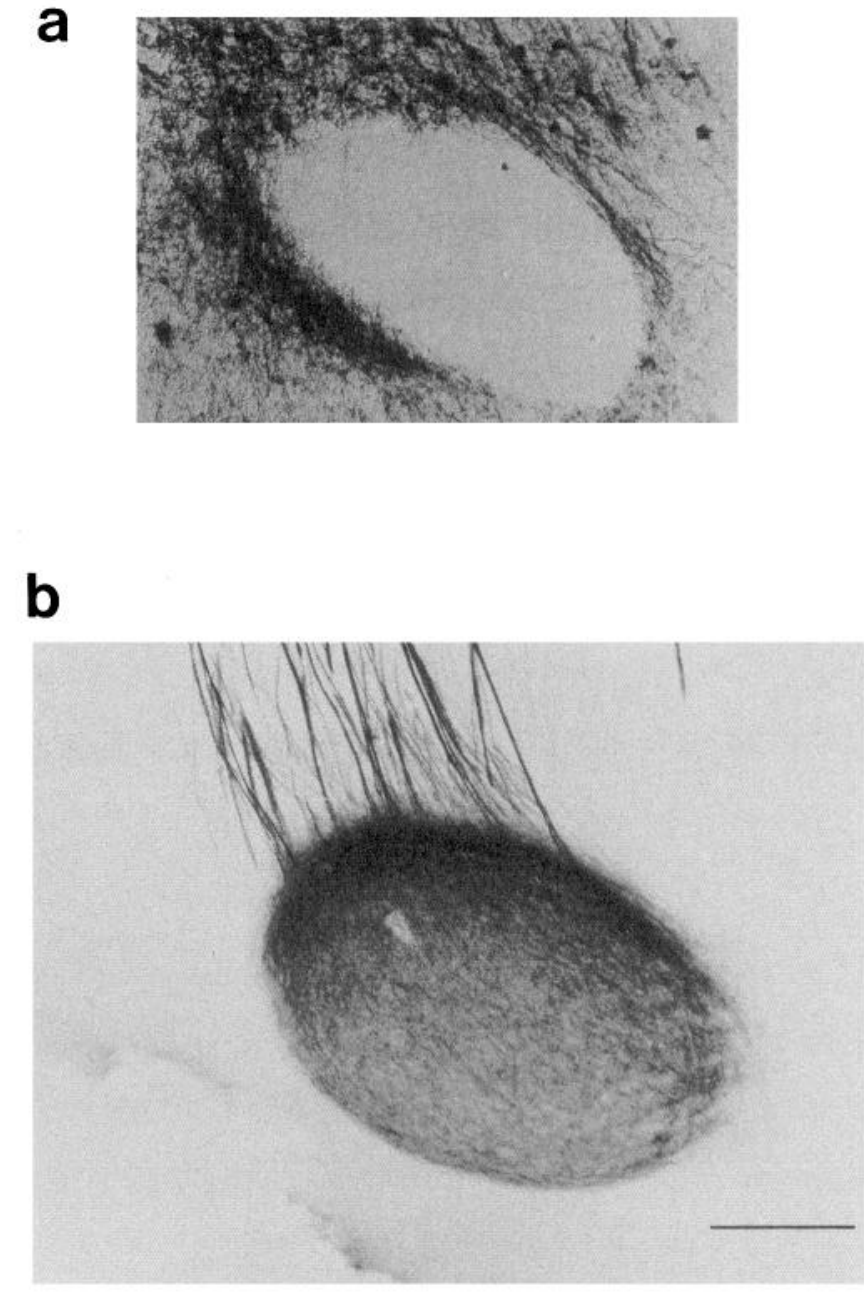

Figure 3. HVc axons enter RA later in development than do L-MAN axons. $a$, DiI crystals implanted in the paraformaldehyde-fixed brain of a day 23 female finch produced a ring-like pattern of anterograde label outside RA. Section is oriented parasagittally, with dorsal to the top and rostral to the right. $b$, DiI crystals implanted in the fixed brain of an adult male finch produced heavy anterograde label within RA. Section is oriented as in $a$. In $a$ and $b$, fluorescent excitation of DiIlabeled material was used to photooxidize DAB. Scale bar: $200 \mu \mathrm{m}$ for $a ; \sim 290 \mu \mathrm{m}$ for $b$.

transient synaptic connections with neurons in the waiting compartment. To test this hypothesis, a total of 22 cells situated located immediately dorsal to RA were impaled with intracellular electrodes in parasagittal slices. Cells within the waiting compartment were classified as neurons because of their capacity to fire action potentials in response to depolarizing currents. Twenty of 22 cells examined within the waiting compartment responded to depolarizing currents of moderate duration (500 $\mathrm{msec}$ ) by initially firing two or three higher-frequency action potentials, followed by a lower frequency train of action potentials that displayed some accommodation (see Fig. $7 a$ ). In some cases, this accommodation was quite pronounced, and the cell would cease firing altogether after several action potentials. The remaining two cells displayed no marked accommodation over the course of the depolarizing current injection. Electrical stimulation within $\mathrm{HVc}$, or the region immediately ventral to it, where HVc axons travel en route to RA, evoked synaptic potentials from all of the waiting compartment neurons encoun- 


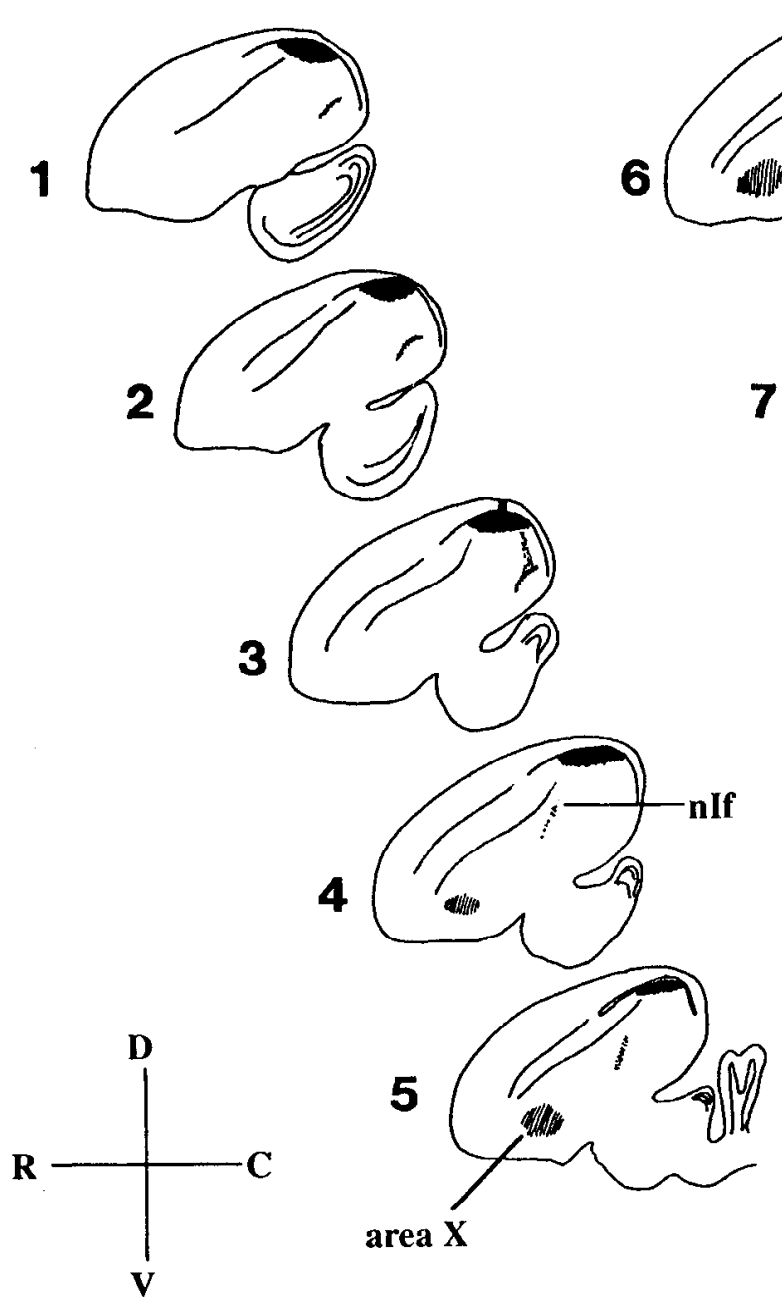

Figure 4. Several areas were labeled by injection of WGA-HRP into the HVc of a day 18 male finch. WGA-HRP was iontophoresed into a region including HVc (solid black area in sections 1-5). Hatched areas represent anterograde label; dots signify the locations of retrogradely labeled cell bodies. Note anterograde label along RA's dorsal border in sections 1-3, and within area X in sections 4-8. Retrograde label in nIf is depicted in sections 4-8, while retrograde label in medial MAN only becomes apparent in sections 9 and 10 . Retrograde labeling within the thalamic nucleus Uva is present in sections 7 and 8 . Section 1 is approximately $2.6 \mathrm{~mm}$ from the midline, and each section represents an advance of $0.15 \mathrm{~mm}$ in the medial direction. $D$, dorsal; $V$, ventral; $R$, rostral; $C$, caudal.

tered in the present study ( 22 of 22 cells) (see Fig. $7 b$ ). These evoked synaptic responses could drive waiting compartment neurons above spike threshold and therefore were classified as excitatory postsynaptic potentials (EPSPs).

\section{Morphology of waiting compartment neurons}

A distinct morphological cell type, closely apposed to RA's dorsal border, was revealed by dye-filling neurons within the waiting compartment, as seen in Figure 8. Their dendrites, which were dorsoventrally flattened, and spanned the dorsal edge of RA, did not enter the nucleus, although they extended freely in the waiting compartment. These neurons also supported a network of axon collaterals local to the parent cell, and in several cases, a lone collateral was observed running dorsally toward HVc. Other axon collaterals of these neurons did not appear to enter RA, although they coursed about the region outside the nucleus.

\section{$R A$ neuronal morphology}

In the male zebra finch, the massive ingrowth of $\mathrm{HVc}$ axons into RA after day 30 is accompanied by a large increase in the volume of the nucleus, presumably because of the addition of large numbers of new synapses (Konishi and Akutagawa, 1985; Herrmann and Arnold, 1991b). In order to characterize the postsynaptic changes that occur within RA concomitant with $\mathrm{HVc}$ axon ingrowth, individual RA neurons were intracellularly stained in brain slices prepared from day $15-65$ finches. All cells filled in this study were of a specific type of RA neuron that fircs action potentials in a repetitive and highly regular fashion, without accommodation, in response to depolarizing currents (see Mooney, 1992).

Although the recording electrode was usually positioned toward the center of RA, regular-spiking RA neurons were distributed throughout RA, including just within its border. Their morphology was studied with both biocytin and Lucifer yellow staining. Eleven of 14 RA neurons filled before day 30 exhibited spinous dendrites; the remaining three neurons were too poorly filled to resolve whether or not spines were present. Ten of 11 RA neurons filled in slices after day 30 also had spinous dendrites; the 11 th cell was too poorly filled to detect if spines were present.

Confocal images were generated of Lucifer yellow-filled RA neurons in brain slices from birds less than $30 \mathrm{~d}$ of age. When 

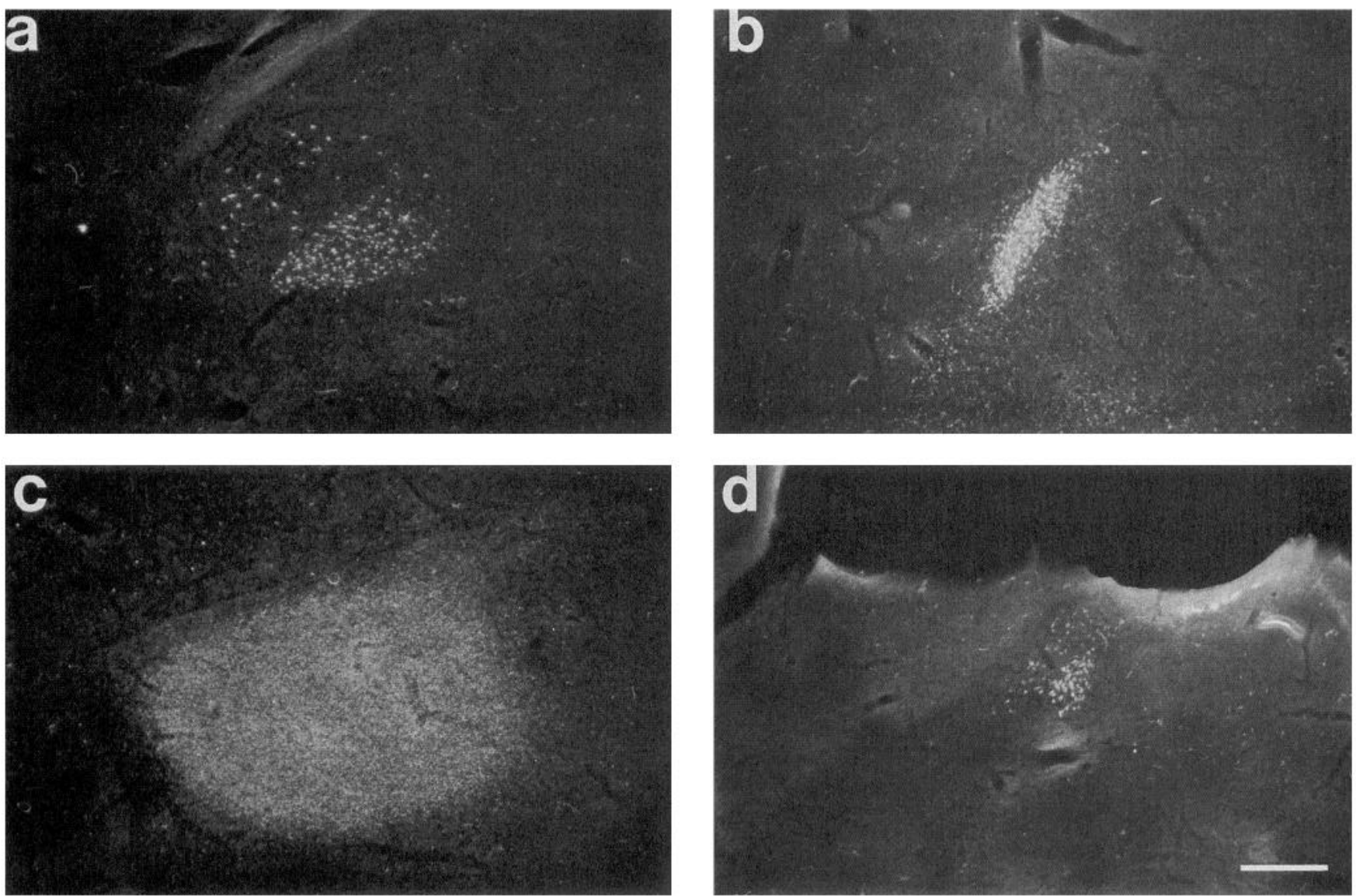

Figure 5. Higher-power dark-field photomicrographs of the material in this figure show retrograde label in medial MAN (a; from Fig. 4, section 9), retrograde label within nIf ( $b$; from Fig. 4, section 5), anterograde label within area X (c; from Fig. 4, section 6), and retrograde label in the thalamic nucleus Uva ( $d$; from Fig. 4 , section 7). All sections are oriented with rostral to the left, and dorsal upward. Scale bar, $200 \mu \mathrm{m}$ for $a-d$.

located toward the center of RA, repetitive-spiking RA neurons had spinous dendrites oriented about the cell body in a radially symmetric manner (see Fig. 9a). In contrast, when the soma was positioned just within RA's border, this radial symmetry was disrupted because the dendrites respected the boundary of the nucleus (see Fig. 9b). A single RA neuron, filled with Lucifer yellow in a slice prepared from a day 24 male, had pronounced, club-like endings at the tips of many of its dendrites (see Fig. $9 c)$. In other respects, it had the basic features associated with other spinous RA neurons encountered in this study. A confocal reconstruction of this cell illustrated the clear elaboration of dendritic spines, and several collaterals could be observed branching from the main axon in close vicinity of the parent cell body. The dendritic endings, when viewed in greater detail (see Fig. 9d), were enlarged relative to the more proximal dendritic shaft, and then terminated in a very fine distal process. When RA neurons at a variety of ages were also stained with biocytin and reconstructed with the aid of a camera lucida (see Fig. 10), common features could be detected. The dendritic arbors of RA neurons were already quite extensive in those brain slices prepared from birds younger than day 30, but appeared to become more elaborate after day 30 . Regardless of age, the axon collaterals, which had numerous varicosities along their length, were restricted to the volume close to the cell body (see Fig. 10), and when the main axon was filled, no branches were observed after it exited RA.

\section{Discussion}

These experiments illustrate that L-MAN and HVc axons innervate RA at different stages during development. L-MAN terminals are present within RA by day 15 , whereas HVc axons are not detected within RA until 10-15 d later. Before day 25, $\mathrm{HVc}$ terminals ramify extensively in a region immediately dorsal to RA, and certain neurons within this region may function as transient targets for developing $\mathrm{HVc}$ axons. These experiments reveal that although L-MAN and $\mathrm{HVc}$ innervate a common target, RA, they do so with a markedly different developmental time course, suggesting that pathways essential to juvenile song acquisition are formed before those needed for adult song production.

\section{Role of innervation in cell death within $R A$}

The developmentally retarded and sexually dimorphic projection that HVc axons make to RA (Konishi and Akutagawa, 1985), coupled with the observations that severing the HVc axons that project to RA in young male zebra finches (Konishi and Akutagawa, 1987) and chemically lesioning HVc in young, estrogen-treated female zebra finches (Herrmann and Arnold, 1991a), result in the atrophy of RA, has lent support to the hypothesis that the sexual differentiation of RA is regulated by an innervation-dependent mechanism. However, the present finding that L-MAN terminals are present within the female 


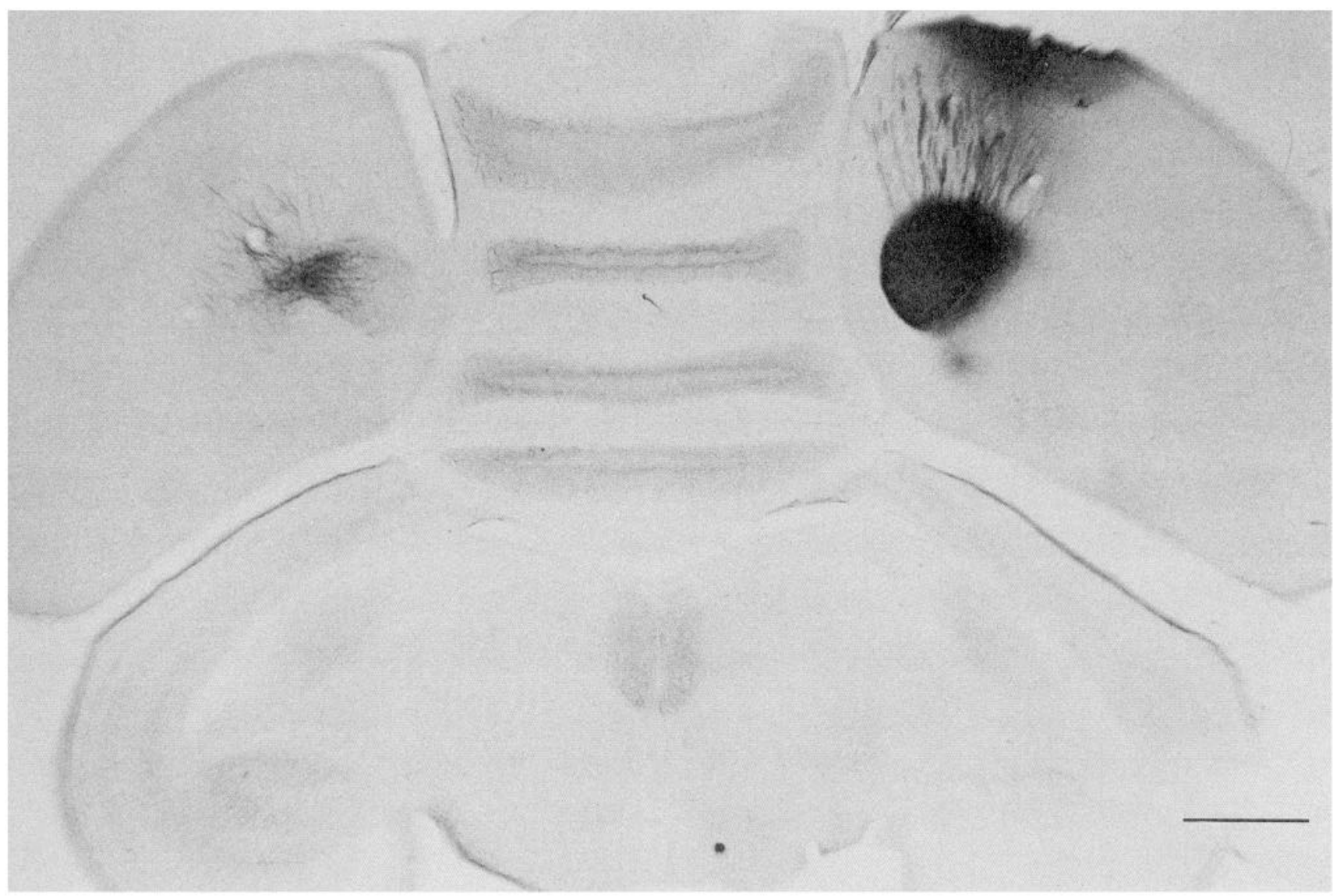

Figure 6. L-MAN and HVc axons enter RA from different angles, as shown in this coronal section through the whole brain of an adult (>day 90) male finch at the level of RA. The left L-MAN and right HVc were implanted with DiI crystals, and DAB was subsequently photooxidized by fluorescently exciting the DiI-labeled axon terminals within RA. In the left hemisphere, axons course down toward RA from their origin in L-MAN (rostral to this plane of section). Note that L-MAN axons enter RA primarily along the lateral edge of the nucleus. In the right hemisphere, HVc axons run in a tract displaced medially to the L-MAN axon tract, and enter RA along its dorsal edge. Scale bar, $1 \mathrm{~mm}$.

RA throughout the period of cell atrophy and death renders a simple innervation-dependent mechanism of RA neuronal survival less plausible. In both male and female zebra finches, the projection from L-MAN to RA forms as early as $12-15 \mathrm{~d}$ after hatching, preceding the period of cell death in the female RA by several weeks. Furthermore, electrophysiological recordings indicate that L-MAN axon terminals have formed functional synapses with RA neurons before day 25 (Mooney, 1992). Apparently, functional synaptic contacts, as supplied by L-MAN axon terminals, are insufficient in preventing RA cell death, suggesting that other mechanisms are responsible for determining the fate of RA neurons. Perhaps $\mathrm{HV}$ c terminals possess unique neurotrophic properties that are essential to RA neuronal survival, or L-MAN and HVc axons interact in a presently unknown manner to prevent cell death within the male RA.

\section{Nature of the waiting compartment}

The mechanisms responsible for the prolonged arrest of $\mathrm{HVc}$ axons at RA's dorsal border are not well understood. Tritiatedthymidine birthdating, coupled with retrograde labeling, have revealed that many of the $\mathrm{HVc}$ neurons ultimately projecting to RA are not born until after day 20 in the zebra finch (Nordeen and Nordeen, 1988). Delayed neurogenesis could explain why some $\mathrm{HVc}$ terminals arrive and enter RA at late stages of development. It does not explain why the axon terminals of earlier- generated HVc neurons, having reached the dorsal border of RA as early as day 15 , do not enter RA immediately, but instead ramify in the region bordering the nucleus. Other factors could contribute to this delay. One possibility is that $\mathrm{HVc}$ axons are delayed from entering RA because they recognize cells immediately dorsal to RA as suitable, albeit temporary, synaptic targets.

Neurons within the waiting compartment display characteristics consistent with their receiving synaptic contact from $\mathrm{HVc}$ axons. In vitro, electrical stimulation of $\mathrm{HVc}$ evoked synaptic potentials from all the waiting compartment neurons that we recorded from. Intracellular staining revealed that a subset of these cells, closely apposed to the dorsal border of RA, had dendrites that spanned the edge of the nucleus in an orientation similar to the HVc axon terminals. These features might be expected of cells that receive transient synaptic input from $\mathrm{HVc}$ axons during early stages of posthatch development. However, we cannot rule out that stimulation in or near HVc evokes EPSPs within the waiting compartment through a polysynaptic pathway, or perhaps by antidromically activating those collaterals that appear to course toward HVc from the waiting compartment.

Developing geniculocortical projections in the mammalian visual system are also characterized by a prolonged "waiting period," in which presynaptic axon terminals are arrested tran- 

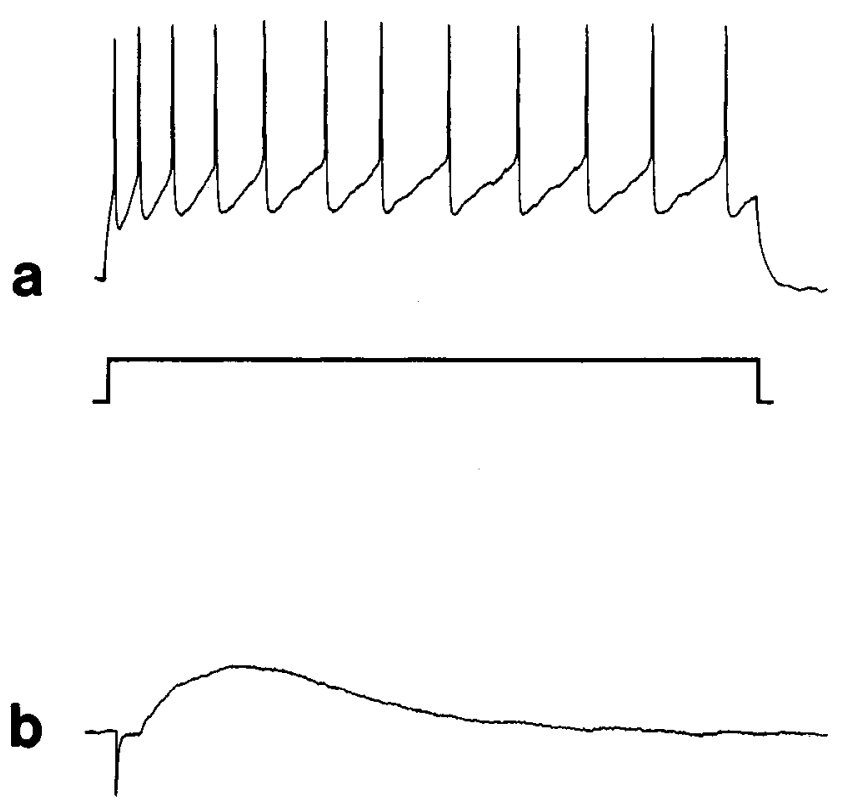

Figure 7. Intracellular recordings, obtained from the cell illustrated in Figure 8, were typical of neurons impaled within the waiting compartment. $a$, Depolarizing the neuron with a 500-msec-long, +0.46 nA current generated a train of action potentials. Note the decrease in firing rate over the duration of the injected current. Resting potential was $-61 \mathrm{mV}$. $b$, Electrical stimulation within $\mathrm{HVc}$ evoked a depolarizing synaptic response from the cell in $a$. At higher stimulus intensities, the PSP elicited an action potential (not shown). The negative-going deflection preceding the synaptic potential marks the stimulus artifact. Calibration: $150 \mathrm{msec}, 40 \mathrm{mV}$ for $a ; 60 \mathrm{msec}, 10 \mathrm{mV}$ for $b$.

siently in a zone adjacent to the mature target (Rakic, 1977; Shatz and Luskin, 1986; Ghosh and Shatz, 1992). Just as in the waiting zone outside the zebra finch RA, intracellular recordings made from the subplate neurons within the visual cortical waiting compartment show that EPSPs can be evoked by stimulating the white matter (Friauf et al., 1990). These EPSPs are probably due to the activation of the waiting geniculate axons themselves, since EM reconstructions show that labeled thalamic axons make synapses on subplate neurons (Herrmann et al., 1991). Geniculocortical development is further characterized by reciprocal connections between neurons in the waiting zone, the subplate neurons, and the lateral geniculate nucleus (McConnell et al., 1989). Despite the striking parallels between the development of the mammalian visual pathway and the development of connections between HVc and RA in the zebra finch, important differences between these two systems are worth noting. First, only one of the two types of afferent input to RA appears to wait before entering the nucleus. In fact, L-MAN axons already have innervated RA successfully during the time that HVc axons are still cxcluded from the nucleus. We cannot rule out the possibility that L-MAN axons are also delayed in entering RA, only at a much earlier stage of development, but a more likely scenario is that the cues retarding HVc axon entry into RA are somehow specific to this pathway. Another difference is that, unlike their counterparts in the song system, lateral geniculate

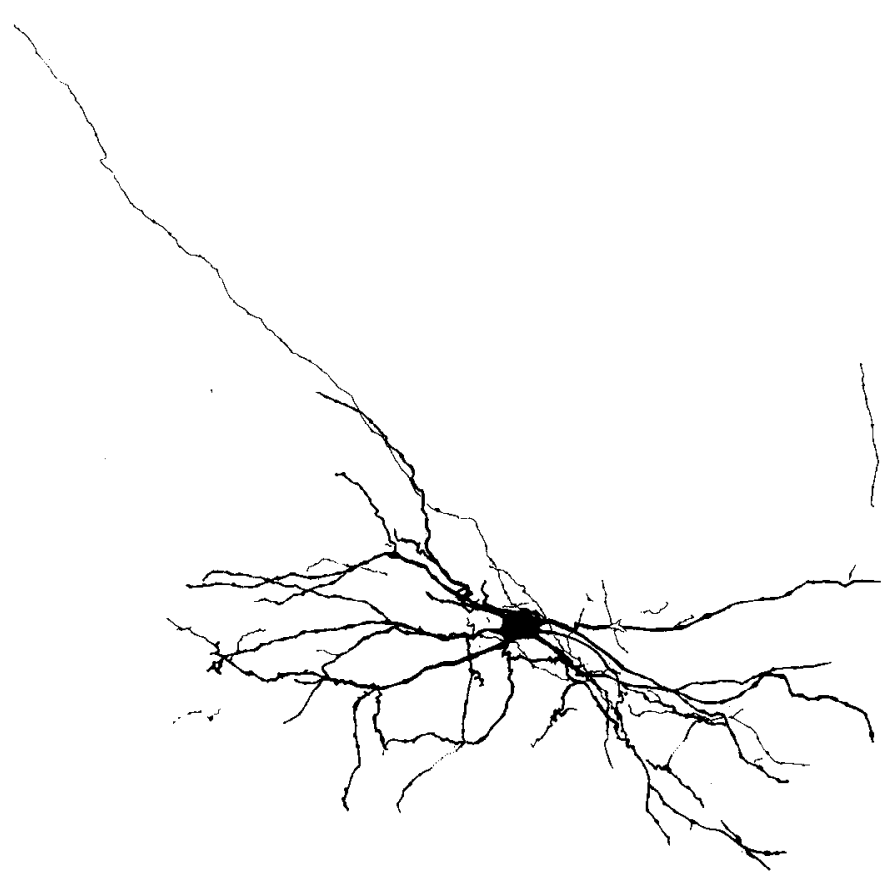

Figure 8. Neuron located within the waiting compartment immediately dorsal to RA. The cell was filled with biocytin in a parasagittal brain slice prepared from a day 18 finch. Note the lone collateral traveling dorsally toward HVc. Dorsal is toward the top, and rostral toward the right.

neurons are born much earlier than their target cell population in layer IV of visual cortex (Shatz, 1983; Luskin and Shatz, 1985). Therefore, LGN axons may wait simply because the neurons that ultimately constitute layer IV have first to migrate from the ventricular zone and then acquire mature characteristics before they can support extrinsic innervation (Shatz et al., 1988). In contrast, many RA neurons are born between embryonic day 6 (E6) and E8 (Konishi and Akutagawa, 1990), long before the $\mathrm{HVc}$ neurons that will eventually innervate them (Nordeen and Nordeen, 1988; Kirn and DeVoogd, 1989). In addition, RA neurons are already functionally innervated by L-MAN axons, as assessed by electrophysiological criteria, as early as day 15 (Mooney, 1992). Thus, HVc axons probably do not wait before entering RA simply because the target is too immature to support innervation.

Regardless of the actual mechanisms regulating the waiting behavior of HVc axons, their eventual entry into RA is accompanied by several postsynaptic changes. In the male, dramatic increases in RA volume, as well as decreases in RA neuronal density, coincide with HVc axonal ingrowth (Konishi and Akutagawa, 1985; Konishi and Akutagawa, 1987). These changes probably reflect the establishment of new synapses between $\mathrm{HVc}$ and RA, as intracellular recordings in brain slices show that $\mathrm{HVc}$ fiber stimulation rarely elicits synaptic responses from RA neurons before day 25 , even though in brain slices prepared from older males, stimulation almost always evokes synaptic potentials within the nucleus (Mooney, 1992). Part of this process of synaptic addition could involve RA dendritic expansion (DeVoogd et al., 1986), perhaps as mediated by the growth-cone like structures that we observed on the tips of individual RA dendrites. Most of the HVc synapses added to RA over this period terminate on the dendritic spines of RA neurons, as EM data in both the canary and the zebra finch show that the ma- 

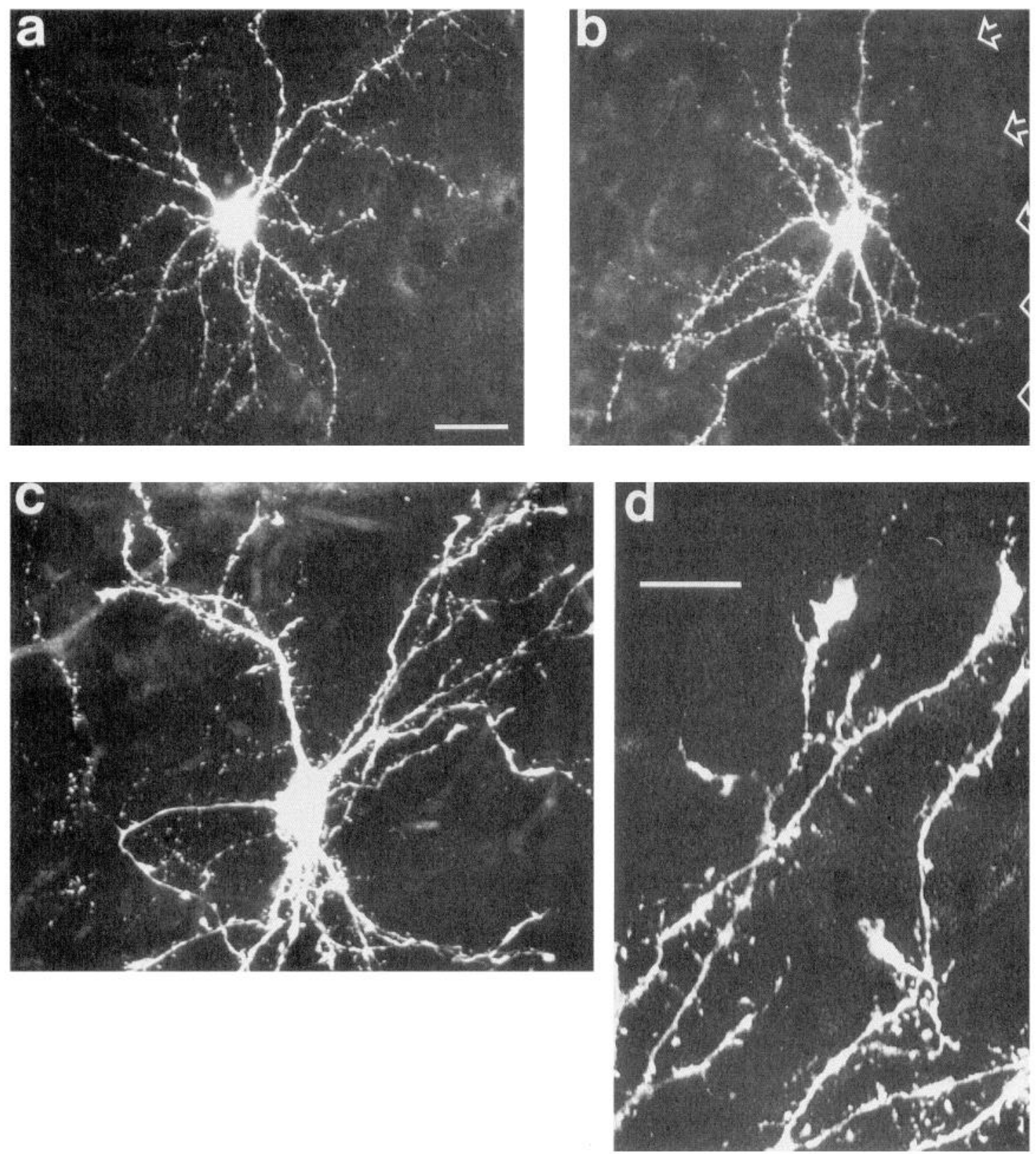

Figure 9. Confocal images of Lucifer yellow-filled RA neurons in slices prepared from finches less than $25 \mathrm{~d}$ of age. $a$, An RA neuron located near the center of RA. Note radially symmetric dendrites, with spines visible along some portions (e.g., upper right quadrant). Slice prepared from a day 17 male finch. $b$, An RA neuron located toward the caudal border of RA (marked by arrows). Dendrites were oriented predominantly away from the boundary of the nucleus. Note dendritic spines. From a day 17 male finch. $c$, An RA neuron from a day 24 male finch. Note the clublike endings on most dendrites. The axon extends from the soma at nine o'clock, and gives rise to several collateral branches. $d$, Higher magnification of upper-right quadrant of neuron in $c$. Note the swollen dendritic tips, in some cases with very thin distal termini. Also note the numerous dendritic spines. a, Scale bars: $a-c, 25 \mu \mathrm{m} ; d, 10 \mu \mathrm{m}$.

jority of HVc axons terminate specifically on these structures (Canady et al., 1988; Herrmann and Arnold, 1991).

\section{The development of the recursive pathway}

The present study indicates that many nuclei of the recursive pathway (i.e., HVc and X; L-MAN and RA) are linked together before certain key connections are established in the direct vocal motor control pathway (i.e., HVc and RA). Before day 20, HVc terminals are present within area $\mathrm{X}$, and L-MAN terminals are present within RA. Other studies have shown that terminals from DLM are present within L-MAN as early as day 15 (John- son and Bottjer, 1992), and that terminals arising from area $X$ are present within DLM by day 20 (Sohrabji et al., 1993). These data, together with the present results, indicate that the entire recursive pathway is anatomically connected by day 20 . In contrast to the early development of the recursive pathway, HVc axons do not form substantial connections with RA until after day 25 . The mechanisms that regulate the differences in the timing of the development of these two pathways are not totally clear, although thymidine studies indicate that $\mathrm{HVc}$ neurons projecting to area $\mathrm{X}$ are born well before those projecting to RA (Alvarez-Buylla et al., 1988; Nordeen and Nordeen, 1988; Kirn 

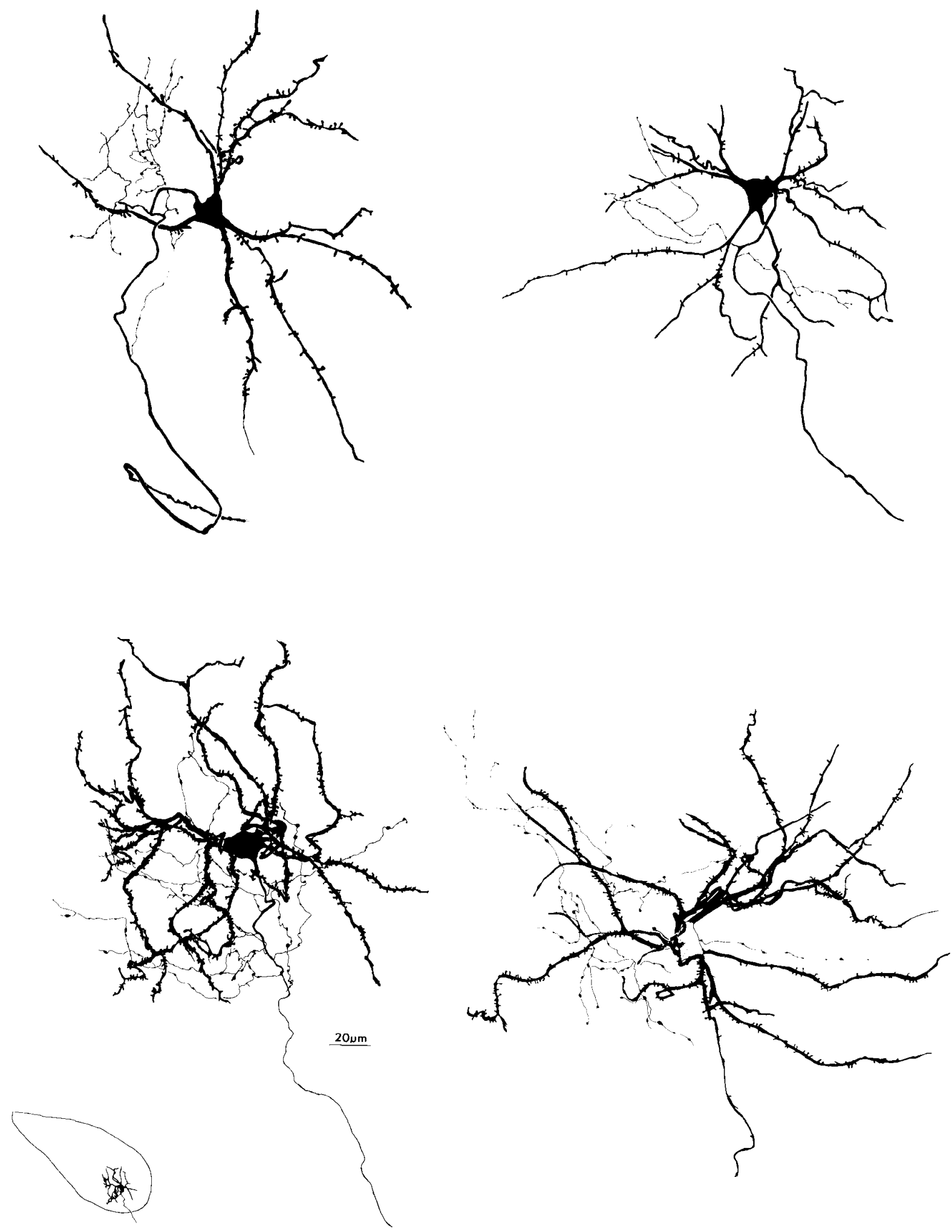

Figure 10. RA ncurons filled with biocytin in slices prepared from younger and older finches, reconstructed with the aid of a camera lucida. The two neurons on the top were filled in brain slices from finches aged less than day 25 . The two neurons on the bottom were filled in slices from a day 55-65 male finch; the axon in the neuron in the lower right corner was not completely recovered. The inset in the lower left corner shows the extent of the dendritic arbor with respect to the outlined boundary of nucleus RA. In all cells, orientation is coronal, with dorsal to the top of the figure, and medial to the right. Scale bars: $20 \mu \mathrm{m}, 100 \mu \mathrm{m}$ for inset. 
and DeVoogd, 1989). The heterochronic neurogenesis of HVc's two efferent subpopulations could provide an initial bias that favors the early development of the recursive pathway.

The developmental differences betwecn these two pathways could have important behavioral implications. Lesion studies support the division of the song control circuit into both a direct vocal motor control pathway, which must be intact for normal song production in the adult, and a recursive pathway, which appears to play an essential role only in the early stages of song development (Nottebohm et al., 1976; Bottjer et al., 1984; Sohrabji et al., 1990; Scharf and Nottebohm, 1991). Recently, songselective auditory responses have been detected in both L-MAN and area $X$ in the adult zebra finch (Doupe and Konishi, 1991). $\mathrm{X}$-projecting HVc neurons, also known to respond selectively to song (Margoliash, 1983), might provide auditory input to the recursive pathway (Katz and Gurney, 1981). If so, a neuronal circuit that exhibits highly specific auditory response properties in the adult is connected by the third posthatch week, closely coinciding with the onset of sensory acquisition, the period when young zcbra finches first begin to listen to and memorize a tutor song. In contrast, connections between two vocal premotor areas, HVc and RA, are not established until 10-15 d later, coinciding quite closely with the onset of subsong, the earliest stage of song production (Immelmann, 1969). Staggering the development of these two functionally distinct pathways might reflect a strategy in which song nuclei involved in sensory acquisition are connected first, and then guide the later-developing connections of the vocal motor control pathway.

\section{References}

Alvarez-Buylla A, Theelen M, Nottebohm F (1988) Birth of projection neurons in the higher vocal center of the canary forebrain before, during; and after song learning. Proc Natl Acad Sci USA 85:87228726.

Bohner J (1990) Early acquisition of song in the zebra finch, Taeniopygia guttata. Anim Behav 39:369-374.

Bottjer SW, Miesner EA, Arnold AP (1984) Forebrain lesions disrupt development but not maintenance of song in passerine birds. Science 224:901-903.

Bottjer SW, Miesner EA, Arnold A (1986) Changes in neuronal number, density and size account for increases in volume of song-control nuclei during song development in zebra finches. Neurosci Lett 67: 263-268.

Bottjer SW, Halsema KA, Brown SA, Miesner EA (1989) Axonal connections of a forebrain nucleus involved with vocal learning in zebra finches. J Comp Neurol 279:312-326.

Canady RA, Burd GD, DeVoogd TJ, Nottebohm F (1988) Effect of testostcronc on input received by an identified neuron type of the canary song system: a Golgi/electron microscopy/degeneration study. J Neurosci 8:3770-3784.

DeVoogd TJ, Norden H, Gould C (1986) Dendritic retraction and spine elimination in females contribute to sex dimorphisms in the avian song system. Soc Neurosci Abstr 12:1214.

Doupe AJ, Konishi M (1991) Song-selective auditory circuits in the vocal control system of the zebra finch. Proc Natl Acad Sci USA 88: 11339-11343.

Friauf E, McConnell SK, Shatz CJ (1990) Functional synaptic circuits in the subplate during fetal and early postnatal development of cat visual cortex. J Neurosci 10:2601-2613.

Ghosh A, Shatz CJ (1992) Pathfinding and target selection by developing geniculocortical axons. J Neurosci 12:39-55.

Godement P, Vanselow H, Thanos S, Bonnhoeffer F (1987) A study in developing visual systems with a new method of staining neurones and their processes in fixed tissue. Development 101:697-713.

Gurney ME (1981) Hormonal control of cell form and number in the zebra finch song system. J Neurosci 1:658-673.

Gurney ME (1982) Behavioral correlates of sexual differentiation in the zebra finch song system. Brain Res 231:153-172.
Gurney ME, Konishi M (1980) Hormone-induced sexual differentiation of brain and behavior in zebra finches. Science 208:1380-1383.

Herrmann K, Arnold AP (1991a) Lesions of HVc block the developmental masculinizing effects of estradiol in the female zebra finch song system. J Neurobiol 22:29-39.

Herrmann K, Arnold AP (1991b) The development of afferent projections to the robust archistriatal nucleus in male zebra finches: a quantitative electron microscopic study. J Neurosci 11:2063-2074.

Herrmann K, Antonini A, Shatz CJ (1991) Thalamic axons make synaptic contacts with subplate neurons in cortical development. Soc Neurosci Abstr 17:899.

Horikawa K, Armstrong WE (1988) A versatile means of intracellular labeling: injection of biocytin and its detection with avidin conjugates. J Neurosci Methods 25:1-11.

Immelmann K (1969) Song development in the zebra finch and other estrildid finches. In: Bird vocalizations (Hinde RA, ed), pp 61-74. London: Cambridge UP

Johnson F, Bottjer S (1992) Growth and regression of thalamic efferents in the song-control system of male zebra finches. J Comp Neurol $326: 442-450$.

Katz LC, Gurney ME (1981) Auditory responses in the zebra finch's motor system for song. Brain Res 211:192-197.

Kirn JR, DeVoogd TJ (1989) Genesis and death of vocal control neurons during sexual differentiation in the zebra finch. J Neurosci 9:3176-3187.

Konishi M, Akutagawa E (1985) Neuronal growth, atrophy and death in a sexually dimorphic song nucleus in the zebra finch. Nature 315: $145-147$.

Konishi M, Akutagawa E (1987) Hormonal control of cell death in a sexually dimorphic song nucleus in the zebra finch. In: Selective neuronal death, pp 173-185. Wiley: Chichester.

Konishi M, Akutagawa E (1990) Growth and atrophy of neurons labeled at their birth in a song nucleus of the zebra finch. Proc Natl Acad Sci USA 87:3538-3541.

Kroodsma DE, Konishi M (1991) A suboscine bird (Eastern phoebe, Sayornis phoebe) develops normal song without auditory feedback. Anim Behav 42:477-488.

I.und RD, Mustari MJ (1977) Development of the geniculocortical pathway in rats. J Comp Neurol 173:289-306.

Luskin MB, Shatz CJ (1985) Neurogenesis of the cat's primary visual cortex. J Comp Neurol 242:611-631.

Marfurt C, Turner DF, Adams C (1988) Stabilization of tetramethylbenzidine (TMB) reaction product at the electron microscopic level by ammonium molybdate. J Neurosci Methods 25:215-223.

Margoliash D (1983) Acoustic parameters underlying the responses of song-specific neurons in the white-crowned sparrow. J Neurosci 3:1039-1057.

McCasland J (1987) Neuronal control of birdsong production. J Neurosci 7:23-29.

McConnell SK, Ghosh A, Shatz CJ (1989) Subplate neurons pioneer the first axon pathway from the cerebral cortex. Science 245:978982.

Mesulam M (1978) Tetramethylbenzidine for horseradish peroxidase neurochemistry: a non-carcinogenic blue reaction product with superior sensitivity for visualizing neural afferents and efferents. J Histochem Cytochem 26:106-117.

Mooney R (1992) Synaptic basis for developmental plasticity in a birdsong nucleus. J Neurosci 12:2464-2477.

Mooney R, Konishi M (1991) Two distinct inputs to an avian song nucleus activate different glutamate receptor subtypes on individual neurons. Proc Natl Acad Sci USA 88:4075-4079.

Nordeen KW, Nordeen EJ (1988) Projection neurons within a vocal motor pathway are born during song learning in zebra finches. Nature 334:149-151.

Nottebohm F, Arnold A (1976) Sexual dimorphism in vocal control areas of the songbird brain. Science 194:211-213.

Nottebohm F, Stokes TM, Leonard CM (1976) Central control of song in the canary, Serinus canarius. J Comp Neurol 165:457-486.

Nottebohm F, Kelley DB, Paton JA (1982) Conncctions of vocal control nuclei in the canary telencephalon. J Comp Neurol 207:344 357.

Okuhata S, Saito N (1987) Synaptic connections of thalamo-cerebral vocal control nuclei of the canary. Brain Res Bull 18:35-44.

Rakic P (1977) Prenatal development of the visual system in the rhesus monkey. Philos Trans R Soc Lond [Biol] 278:245-260. 
Sandell JH, Masland RH (1988) Photoconversion of some fluorescent markers to a diaminobenzidine product. J Histochem Cytochem 36: 555-559.

ScharffC, Nottebohm F (1991) A comparative study of the behavioral deficits following lesions of various parts of the zebra finch song system: implications for vocal learning. J Neurosci 11:2896-2913.

Shatz CJ (1983) The prenatal development of the cat's retinogeniculate pathway. J Neurosci 3:482-499.

Shatz CJ, Luskin MB (1986) The relationship between the geniculocortical afferents and their cortical target cells during the development of the cat's primary visual cortex. J Neurosci 6:3655-3668.

Shatz CJ, Chun JJ, Luskin MB (1988) The role of the subplate in the development of the mammalian telencephalon. In: Cerebral cortex,
Vol 7, Development and maturation of cerebral cortex (Peters A, Jones EG, eds), pp 35-58. New York: Plenum.

Simpson HB, Vicario DS (1990) Brain pathways for learned and unlearned vocalizations in zebra finches. J Neurosci 10:1541-1556.

Sohrabji F, Nordeen EJ, Nordeen KW (1990) Selective impairment of song learning following lesions of a forebrain nucleus in the juvenile zebra finch. Behav Neural Biol 53:51-63.

Sohrabji F, Nordeen EJ, Nordeen KW (1993) Characterization of neurons born and incorporated into a vocal control nucleus during avian song learning. Brain Res 620:335-338.

Stewart WW (1978) Functional connections between cells as revealed by dye-coupling with a highly fluorescent naphthalimide tracer. Cell 14:741-759. 